\title{
Motility, adhesion and c-di-GMP levels influence the endophytic colonization of rice by Azoarcus sp. CIB
}

Helga Fernandez-Llamosas

Centro de Investigaciones Biologicas

\section{Eduardo Diaz}

Centro de Investigaciones Biologicas

Manuel Carmona ( $\nabla$ mcarmona@cib.csic.es)

Centro de Investigaciones Biologicas

\section{Research article}

Keywords: flagella, pili type IV, c-di-GMP, Azoarcus, endophyte, plant bacteria interaction

Posted Date: July 28th, 2020

DOl: https://doi.org/10.21203/rs.3.rs-47603/v1

License: (1) This work is licensed under a Creative Commons Attribution 4.0 International License.

Read Full License

Version of Record: A version of this preprint was published at Microorganisms on March 8th, 2021. See the published version at https://doi.org/10.3390/microorganisms9030554. 
9 Helga Fernández-Llamosas ${ }^{1}$, Eduardo Díaz ${ }^{1}$, and Manuel Carmona ${ }^{\# 1}$

11 1. Microbial and Plant Biotechnology Department. Centro de Investigaciones

12 Biológicas Margarita Salas-CSIC. Ramiro de Maeztu 9, 28040 Madrid, Spain

15 \# Correspondence: Manuel Carmona

16 mcarmona@cib.csic.es

17

18

19

20 


\section{Abstract}

22 Background: Proficient crop production is needed to ensure the feeding of a growing 23 global population. The association of bacteria with plants plays an important role in the 24 health state of the plants contributing to the increase of agricultural production. 25 Endophytic bacteria are ubiquitous in most plant species providing, in most cases, plant 26 promotion properties. However, the knowledge on the genetic determinants involved in 27 the colonization of plants by endophytic bacteria are still poorly understood.

29 Results: In this work we have used a genetic approach based on the construction of 30 fliM, pilX and eps knockout mutants to show that the motility mediated by a functional 31 flagellum and the pili type IV, and the adhesion modulated by exopolysaccarides are 32 required for the efficient colonization of rice roots by the endophyte Azoarcus sp. CIB. 33 Moreover, we have demonstrated that expression of an exogenous diguanylate cyclase 34 or phophodiesterase, which causes either an increase or decrease of the intracellular 35 levels of the second messenger cyclic di-GMP (c-di-GMP), respectively, leads to a 36 reduction of the ability of Azoarcus sp. CIB to colonize rice plants.

38 Conclusions: Here we present results demonstrating the unprecedented role of the universal second messenger cyclic-di-GMP in plant colonization by an endophytic 40 bacterium, Azoarcus sp. CIB. The involvement of bacterial motility and adherence 41 mediated by the bacterial flagellum, pili type IV and exopolysaccharides in the colonization of rice by strain CIB is also shown. These studies pave the way to further strategies to modulate the interaction of endophytes with their target plant hosts. 
45 Keywords: flagella, pili type IV, c-di-GMP, Azoarcus, endophyte, plant bacteria interaction

\section{Background}

Plant associated bacteria play a fundamental role in the healthy state of the plant contributing to its nutrition, development and defence [1-3]. A good number of the associated bacteria colonize the plant tissues as endophytes being roots a major target for endophytic colonization [2]. The effective root colonization by endophytic bacteria involves the coordinated expression of a number of gene factors, many of which are still poorly understood [4-7]. Several comparative studies of the genomes of endophytic bacteria were performed trying to establish the genes involved in plant colonization [2, 8-11]. Hardoim et al. [9] compared 40 genomes of endophytic bacteria with genomes of bacterial plant pathogens, bacteria that colonize the rhizosphere and bacteria from the rhizobia group, in order to establish the determinants that differentiate endophytes from non-endophytic bacteria able to interact with plants. Some properties such as motility,

60 chemotaxis and adherence were considered crucial for initiating endophytic

61 colonization. Endophytes are attracted to the root by plant exudates [2], therefore, bacterial motility plays an important role in plant colonization and, in fact, most of the known endophytes have flagella [11]. Chemotaxis towards the plant varies greatly between the different species of endophytes according to the rank of their preferred host [8]. For example, while in Gluconacetobacter diazotrophicus only 12 genes related to transmembrane receptors, and two-component response regulators are involved in the signal transduction for chemotaxis, the genome of Azoarcus sp. BH72 has 51 such genes, a number similar to that of Burkholderia phytofirmans PsJN [11]. 
The flagellum is considered one of the first bacterial factors that come into

70 contact with the plant, activating the induced systemic resistance [12]. It has been reported that the Azoarcus sp. BH72 flagellum has an active role during the effective endophytic colonization of rice roots [13]. Once the bacteria contacted with plant roots, adherence and motility of the twitching type mediated by the pili type IV becomes especially important $[8,14]$. Thus, the presence of functional pili seems to be also essential for the colonization of rice by Azoarcus sp. BH72 [4, 15]. After the adhesion of the bacteria to the roots microcolonies are formed involving the essential participation of exopolysaccharides and lipopolysaccharides [16-18], as it has been reported in the colonization of rice roots by Herbaspirillum seropedicae [19] and $G$. diazotrophicus [20]. In fact, bacterial exopolysaccharide is related with a multitude of vital functions for the cell, supporting the cohesion and adhesion to biotic and abiotic surfaces through cell aggregation and participating in biofilm formation [21]. In fact, some reports have suggested the participation of exopolysaccharide in the establishment of symbiotic and plant-bacterial interactions between rhizobia and legumes [22], and in the rhizosphere interactions of some strains of P. fluorescens [23] or endophytes such G. diazotrophicus [20].

Cyclic di-GMP (c-di-GMP) is a second universal messenger in prokaryotes that controls many bacterial processes such as the transition from a planktonic to a sessile state favouring the establishment of biofilms and modulating bacterial virulence [24, 25]. In fact, it has been reported that the levels of c-di-GMP in bacteria control the synthesis of exopolysaccharides, adhesins and the formation of biofilms [26-30], hence regulating, among others, colony morphology [31, 32], quorum sensing processes [33], cell motility [34-37], nodulation [30, 38] and virulence [39, 40]. However, reports on the role of c-di-GMP in plant-bacteria interactions are scare. The few available studies 
94 have mainly focused on the regulation of virulence in plant pathogenic bacteria [41]

95 such as Pseudomonas syringae [42, 43], P. savastanoi [42], Xanthomonas campestris

96 [44-46] or X. oryzae [47, 48], and in the study of the interaction between plants and

97 symbiotic bacteria $[42,49]$. The results obtained from these studies are disparate. Thus,

98 whereas increasing c-di-GMP levels by the overexpression of the diguanylate cyclase

99 (DGC) $\mathrm{PleD}$ in pathogenic strains $P$. syringae pv. tomato and $P$. syringae pv.

100 phaseolicola reduces the expression of the type III secretion system (associated with

101 pathogenesis) without affecting virulence, the overexpression of PleD in P. savastanoi

102 does not affect the expression of the secretion system but delays the appearance of

103 necrosis [42]. In general, high concentrations of cyclic di-GMP promote biofilm

104 formation, aggregation, attachment, and reduced motility of pathogens such as Vibrio

105 cholerae [50], Xanthomonas campestris pv. campestris [51] or Yersinia pestis [52]. In

106 symbionts, the study of how c-di-GMP levels affect interactions, for example between

107 Rhizobium etli and Phaseolus vulgaris or between R. leguminosarum and Vicia sativa,

108 have shown that, in both cases, high levels of c-di-GMP favour adhesion to the roots of

109 the plant, associated with a greater formation of biofilm, but negatively affect later

110 stages, reducing nitrogen fixation and, consequently, plant growth [42]. Nevertheless,

111 and as far as we know, there are no reports on the role of c-di-GMP in plant

112 colonization by endophytes.

113 Azoarcus sp. CIB is a beta-proteobacterium, facultative anaerobic (denitrifying)

114 strain able to colonize rice roots as an endophyte [53] that display plant growth

115 promoting traits such as the ability to fix nitrogen, solubilize inorganic phosphate,

116 produce the plant growth hormone indoleacetic acid [53] and promote the rice plant

117 growth under certain environmental stress conditions [54]. Some genetic determinants

118 likely involved in the endophytic interaction, such as the presence of flagella and pili 
119 type IV, can be inferred from the genome sequence of strain CIB [55]. In addition,

120 strain CIB owns some other interesting biotechnological properties such as the ability to

121 degrade toxic aromatic compounds, e.g. toluene/xylene, under aerobic and anaerobic

122 conditions [56, 57], and tolerate high concentrations of certain metals and metalloids for

123 their conversion into metal nanoparticles of industrial value [58, 59]. All these features

124 make strain CIB significantly different to the typical Azoarcus endophytic strains, and

125 more closely related to members of the new genus Aromatoleum [60].

126 The aim of this work is to explore the role of the flagellum, pili type IV and

127 exopolysaccarides on the colonization of rice roots by Azoarcus sp. CIB. Since the

128 second messenger c-di-GMP is connected with motility and adhesion, in this work we

129 investigated if the levels of c-di-GMP also control the ability of the bacterium to

130 colonize plant, an aspect scarcely explored in endophytes.

132 Results and Discussion

134 A functional flagellum and pili type IV are required for rice colonization of 135 Azoarcus sp. CIB

136 As mentioned in the Introduction, bacterial motility plays an important role in plant

137 colonization. The flagellum has traditionally been regarded as the main responsible for

138 bacterial motility. Three gene clusters predicted to control the synthesis and regulation

139 of the flagellum have been identified at three different positions of the genome of

140 Azoarcus sp. CIB [55, Supplementary Table S1 in Additional file 1]. We then checked

141 whether a mutation that abolish flagellum functionality may have an effect on the

142 endophytic colonization of rice by strain CIB. 
144 constructed the mutant strain Azoarcus sp. CIBdfliM (Table 1). This strain harbors a 145 disruptional insertion of the fliM (AzCIB_0962) gene, encoding the FliM protein of the

$146 \mathrm{C}$ ring which has been shown to be directly involved in flagellum movement and the

147 flagellar export apparatus [61-64]. To check whether the fliM mutant strain showed an

148 altered motility phenotype, we performed bacterial swimming assays. As shown in

149 figure $1 \mathrm{a}$, the movement of the mutant cells was significantly diminished (around 50\%)

150 with respect to that of the parental strain, hence suggesting an important loss of

151 functionality of the flagellum in Azoarcus sp. CIBdfliM strain. We then checked the

152 ability of the mutant strain to colonize rice seedlings. Interestingly, the number of

153 endophytes recovered after inoculation of rice seedlings with Azoarcus sp. CIBdfliM

154 strain was around an order of magnitude lower $\left(3.4 \times 10^{3}\right.$ per $g$ of roots $)$ than those 155 recovered from seedlings inoculated with the wild type CIB strain $\left(4.5 \times 10^{4}\right.$ per $\mathrm{g}$ of

156 roots) (Fig. 1b). These results reveal an important role of the flagellum at some stage of

157 the endophytic colonization of rice by Azoarcus sp. CIB. These results are in agreement

158 with previous reports showing that deletion of the fliC3 gene, encoding the main

159 flagellin (FliC) of the flagellum, in the endophyte Azoarcus sp. BH72 strain leads to a 160 significant decrease of around $80 \%$ in the plant colonizing capacity on competition 161 assays between the wild type and the mutant strain [13], hence supporting that the 162 flagellum is involved in the Azoarcus-plant interaction.

163 Different studies conducted on Azoarcus spp. strains have concluded that pili 164 type IV are needed for plant colonization since they are responsible of adhesion and 165 movement to the plant roots $[4,13,15,65]$. The genes predicted to be responsible for 166 the synthesis of pili type IV in Azoarcus sp. CIB are organized in several genes clusters 167 distributed along the genome [55, Supplementary Table S1 in Additional file 1]. In 
168 order to analyze if the minor pilin PilX from Azoarcus sp. CIB is involved in the

169 colonization of rice root, we constructed an Azoarcus sp. CIBdpilX mutant strain 170 containing a disruption of the pilX gene (AzCIB_3117) (Table 1). The motility

171 (swarming pattern) of the pilX mutant strain was reduced by $40 \%$ compared to that

172 observed with the wild-type strain (Fig. 2a), which is in agreement with the already

173 observed lower motility in pil mutant bacterial strains $[66,67]$ and confirms that the pil

174 genes indeed encode proteins that participate in the motility apparatus in Azoarcus sp.

175 CIB. Interestingly, the plant colonization ability of the Azoarcus sp. CIBdpilX strain

176 was more than one order of magnitude lower than that of the parental CIB strain (Fig.

177 2b). Therefore, these results allowed us to conclude that pili type IV are involved in the

178 interaction of the CIB strain with rice. Our results in strain CIB are in agreement with

179 those reported in Azoarcus sp. BH72 where a deletion of pilX did not inhibit the 180 synthesis of the pili but affected its functionality $[68,69]$ and decreased by $80 \%$ the 181 plant colonizing capacity of the mutant strain $[4,15]$.

182 In summary, all these results taken together indicate that both, flagellum and pili

183 type IV are needed for the interaction of Azoarcus sp. CIB with rice.

185 Role of the genes involved in exopolysaccharide modification in the interaction 186 between Azoarcus sp. CIB and rice

187 As mentioned in the Introduction, exopolysaccharides have an important role in plant188 bacteria interactions [20, 22, 23]. In the genome of Azoarcus sp. CIB we have identified 189 three gene clusters putatively involved in the synthesis and modification of 190 exopolysaccharides [55, Supplementary Table S1 in Additional file 1]. Previous results

191 have shown that the gene cluster $A z C I B \_0813-0833$ was strongly induced at the 192 transcriptional level in the presence of rice extracts [54]. To analyze the potential role of 
193 this gene cluster in the colonization of rice roots by the CIB strain, it was inactivated by 194 insertional disruption at the $A z C I B \_0818($ eps $F)$ gene. The surface of the colonies of the

195 Azoarcus sp. CIBdepsF mutant strain grown on a solid culture medium supplemented

196 with Congo Red dye [70] showed a rugose phenotype in contrast to the smooth

197 phenotype shown by colonies of the wild-type strain (Fig. 3a). These changes in colony

198 morphology strongly suggest the existence of significant alterations in the 199 exopolysaccharide of the epsF mutant strain [71], hence indicating that the eps genes 200 are indeed involved in exopolysaccharide synthesis/modification. The next step was to 201 study the ability of the strain Azoarcus sp. CIBdepsF to colonize rice roots as an 202 endophyte. The plant colonization results showed that the number of Azoarcus sp. 203 CIBdeps $F$ endophytes recovered from rice roots $\left(1.65 \times 10^{4}\right.$ bacteria per $\mathrm{g}$ of roots $)$ was $20436 \%$ lower than that obtained from roots inoculated with the parental strain Azoarcus 205 sp. CIB ( $4.57 \times 10^{4}$ bacteria per g of roots) (Fig. 3b). Therefore, the results obtained reveal that the inactivation of the eps cluster reduces the ability of Azoarcus sp. CIB to interact with the rice plant. These results provide strong experimental support on the role of the exopolysaccharide(s) promoting the endophytic lifestyle in members of the

209 Azoarcus/Aromatoleum group.

210

\section{1 c-di-GMP levels influence the endophytic lifestyle of Azoarcus sp. CIB}

212 As mentioned in the Introduction, c-di-GMP is a second messenger involved in the

213 regulation of many bacterial functions. However, its role in beneficial plant-bacteria

214 interactions and, more specifically, in their endophytic relationships, is poorly studied 215 and far to be understood. Since the production and/or functionality of pili type IV, 216 flagellum and exopolysaccharide (all of which were shown above to be involved in the 217 Azoarcus sp. CIB-rice interactions) have been related with the intracellular levels of c- 
218 di-GMP in bacteria [72-74], it was tempting to speculate that c-di-GMP could be also

219 regulating the endophytic lifestyle of strain CIB. To study further the proposed new

220 function of c-di-GMP in bacterial endophytes, we checked recombinant Azoarcus sp.

221 CIB strains containing different intracellular levels of c-di-GMP. To this end, we used

222 Azoarcus sp. CIB (pIZ2133), expressing the PA2133 c-di-GMP phosphodiesterase from

223 P. aeruginosa PAO1 [26], and Azoarcus sp. CIB (pIZ4959), expressing the PP4959

224 diguanilate cyclase from P. putida KT2440 [75], two strains that show reduced or increased levels of c-di-GMP, respectively, with respect to those of the parental strain Azoarcus sp. CIB (pIZ1016) [76, Table 1]. To confirm that the two recombinant strains showed the phenotypes anticipated according to the variations in c-di-GMP levels [25], we analyzed first their swarming and swimming motility. As expected, whereas Azoarcus sp. CIB (pIZ2133) (reduced c-di-GMP levels) showed an increased swarming and swimming motility, the strain Azoarcus sp. CIB (pIZ4959) (increased c-di-GMP levels) showed a reduced swarming and swimming motility with respect to that of the control strain (Fig. 4). The growth rates of the CIB control strain and its derivative strains CIB (pIZ2133) and CIB (pIZ4959) were similar (data not shown), so the observed different motility cannot be attributed to differences in their cell growth. The morphology of the colonies was later analysed and whereas Azoarcus sp. CIB (pIZ2133) generated smoother and more plain colonies than the control strain, Azoarcus sp. CIB (pIZ4959) showed rough colonies (Fig. 4), which is consistent with a higher exopolysaccharide synthesis [25].

240 (pIZ2133) and Azoarcus sp. CIB (pIZ4959) strains might influence their plant

241 colonization abilities, rice seedlings colonization tests were performed. As shown in

242 figure 5, the number of endophytes recovered from seedlings inoculated with Azoarcus 
sp. CIB (pIZ2133) cells ( $1.46 \times 10^{3}$ bacteria per $g$ of root), was more than one order of

244 magnitude lower than the number of endophytes recovered after inoculation with the

245 CIB control strain $\left(2.5 \times 10^{4}\right.$ bacteria per $g$ of root $)$. On the other hand, inoculation with

246 the strain Azoarcus sp. CIB (pIZ4959) led to $7.63 \times 10^{3}$ endophytes per $\mathrm{g}$ of root, which

247 represents a loss of efficiency in colonization of $70 \%$ with respect to the control strain.

248 Therefore, these data suggest that either the artificial decrease or increase of c-di-GMP

249 levels in Azoarcus sp. CIB affect negatively the endophytic colonization of rice by this

250 bacterium. These results are in agreement with previous observations that any

251 modification in the homeostasis of c-di-GMP negatively affects the interactions

252 between the plant and pathogenic or symbiont bacteria [41-43]. These results can be

253 explained by taken into account that both motility and adhesion are needed for

254 successful plant colonization [2]. Thus, an increase in c-di-GMP levels leads to greater

255 adhesion but, at the same time, to a decrease in bacterial motility; conversely, a decrease

256 of c-di-GMP levels enhance bacterial motility but are detrimental for adhesion and

257 formation of microcolonies needed for the entrance of the bacteria to the internal tissues

258 of the plant $[2,77]$.

259 To try to determine if the modification of c-di-GMP levels in Azoarcus sp. CIB

260 affected the transcription of genes involved in bacterial motility and/or

261 exopolysaccharide formation, an expression analysis of the pilY1 gene (encodes a

262 protein for the synthesis and stabilization of pili type IV), fliC gene (encodes a structural

263 protein of the flagellum) and the epsF gene (encodes a protein for exopolysaccharide

264 modification) was performed. The results obtained revealed that the expression of the

$265 e p s F$ gene was not significantly altered in any of the two strains that have modified

266 levels of c-di-GMP, i,e., Azoarcus sp. CIB (pIZ2133) and Azoarcus sp. CIB (pIZ4959)

267 (Fig. 6). These results suggest that c-di-GMP does not control the exopolysaccharide 
genes at the transcriptional level, pointing to a post-transcriptional control, as already

269 described for exopolysaccharide genes in other bacteria [78], as a more likely regulatory mechanism. Similarly, the expression of the pilY1 and fliC genes was not significantly

271 altered in Azoarcus sp. CIB (pIZ2133) (reduced c-di-GMP levels) when compared with

272 their expression in the control strain (Fig. 6), suggesting that the increased motility 273 observed in the former strain might be controlled by a c-di-GMP dependent post274 transcriptional regulation as already shown in P. aeruginosa PAO1 [79]. In contrast, the expression of pilY1 and fliC genes was 3-3.5 times lower in the strain Azoarcus sp. CIB (pIZ4959) than in the control strain (Fig. 6), suggesting that the increase of c-di-GMP

277 levels leads to a transcriptional repression of such genes. The repression of the pil and $278 f l i$ genes in response to elevated cellular levels of c-di-GMP was previously observed in 279 other bacteria such as $V$. cholerae [80, 81], and is in agreement with the reduced 280 motility observed in swarming and swimming assays (Fig. 4). It is known that the c-di-

281 GMP mediated transcriptional regulation of motility genes takes place through the FleQ 282 regulator in $P$. aeruginosa and $P$. putida $[34,82,83]$, or through alterations in 283 chemotactic machinery affecting receptors with PilZ domains [84, 85]. Since Azoarcus 284 sp. CIB does not have a FleQ ortholog and only a protein with a putative PilZ domain 285 has been identified by genome search, it is currently difficult to predict the signaling cascade involved in the transcriptional control mediated by c-di-GMP on the pil and fli genes in the CIB strain. In summary, all the results presented here show for the first time how the modification of intracellular levels of c-di-GMP in an endophytic bacterium affects its ability to colonize the host plant, and they reveal an unnoticed role of c-di-GMP in bacteria controlling the endophytic lifestyle. More work needs to be done to elucidate

292 the signaling cascade that responds to the levels of c-di-GMP in Azoarcus sp. CIB. 


\section{Conclusions}

295 The results of the present study describe the participation of the motility mediated by 296 the flagellum and pili type IV, the adhesion modulated by exopolysaccharides and, 297 remarkably, the unnoticed participation of the intracellular levels of c-di-GMP in the 298 colonization of rice roots by Azoarcus sp. CIB. More experiments needs to be 299 developed to understand the complete landscape of molecular determinants involved in 300 the signaling cascade that responds to the levels of c-di-GMP in Azoarcus sp. The

301 results of these experiment might be used to set strategies to modulate the interaction of 302 endophytes with their target plant hosts.

\section{Methods}

305 Strains, seeds and plasmids used

306 The bacterial strains and plasmids used in this work are listed in Table 1. Azoarcus sp. 307 strain CIB was deposited in the Spanish Type Culture Collection (CECT \#5669). Seeds 308 from Oryza sativa L. GLEVA were kindly provided by Castells Seeds Co. (Spain).

\section{Bacterial growth conditions}

311 Azoarcus strains were grown on MC medium (MA basal medium plus trace elements

312 and vitamins). MA basal medium is composed of the following, per liter of distillated 313 water: $0.33 \mathrm{~g}$ of $\mathrm{KH}_{2} \mathrm{PO}_{4}, 1.2 \mathrm{~g}$ of $\mathrm{Na}_{2} \mathrm{HPO}_{4}, 0.11 \mathrm{~g}$ of $\mathrm{NH}_{4} \mathrm{Cl}, 0.1 \mathrm{~g} \mathrm{MgSO} \mathrm{M}_{4} 7 \mathrm{H}_{2} \mathrm{O}$ and

$3140.04 \mathrm{~g}$ of $\mathrm{CaCl}_{2}(\mathrm{pH}$ 7.5) supplemented with trace elements (stock solution 100x: $1.5 \mathrm{~g}$ 315 of nitrilotriacetic acid, $3 \mathrm{~g}$ of $\mathrm{MgSO}_{4} \times 7 \mathrm{H}_{2} \mathrm{O}, 0.5 \mathrm{~g}$ of $\mathrm{MnSO}_{4} \times 2 \mathrm{H}_{2} \mathrm{O}, 1 \mathrm{~g}$ of NaCl, 0.1 $316 \mathrm{~g}$ of $\mathrm{FeSO}_{4} \times 7 \mathrm{H}_{2} \mathrm{O}, 0.18 \mathrm{~g}$ of $\mathrm{CoSO}_{4} \times 7 \mathrm{H}_{2} \mathrm{O}, 0.1 \mathrm{~g}$ of $\mathrm{CaCl}_{2} \times 2 \mathrm{H}_{2} \mathrm{O}, 0.18 \mathrm{~g}$ of $\mathrm{ZnSO}_{4} \times$ $3177 \mathrm{H}_{2} \mathrm{O}, 0.01 \mathrm{~g}$ of $\mathrm{CuSO}_{4} \times 5 \mathrm{H}_{2} \mathrm{O}, 0.02 \mathrm{~g}$ of $\mathrm{KAl}\left(\mathrm{SO}_{4}\right)_{2} \times 12 \mathrm{H}_{2} \mathrm{O}, 0.01 \mathrm{~g}$ of $\mathrm{H}_{3} \mathrm{BO}_{3}, 0.01 \mathrm{~g}$ 
318 of $\mathrm{Na}_{2} \mathrm{MoO} \times 2 \mathrm{H}_{2} \mathrm{O}, 0.025 \mathrm{~g}$ of $\mathrm{NiCl}_{2} \times 6 \mathrm{H}_{2} \mathrm{O}$ and $0.3 \mathrm{mg}$ of $\mathrm{Na}_{2} \mathrm{ScO}_{3} \times 5 \mathrm{H}_{2} \mathrm{O}(\mathrm{pH} 6.5)$

319 per liter of deionized water), vitamin solution (stock 1,000x: $20 \mathrm{mg}$ of biotin, $20 \mathrm{mg}$ of 320 folic acid, $10 \mathrm{mg}$ of pyridoxine- $\mathrm{HCl}, 50 \mathrm{mg}$ of thiamine- $\mathrm{HCl} \times 2 \mathrm{H}_{2} \mathrm{O}, 50 \mathrm{mg}$ of 321 riboflavin, $50 \mathrm{mg}$ of nicotinic acid, $50 \mathrm{mg}$ of calcium $D$-pantothenic acid, $50 \mathrm{mg}$ of 322 vitamin $\mathrm{B} 12$, and $50 \mathrm{mg}$ of $p$-aminobenzoic acid per liter of distilled water) [56]. As 323 carbon source, $0.2 \%(\mathrm{w} / \mathrm{v})$ pyruvate was added. When needed, bacterial strains were 324 also grown on a variant of the VM-ethanol rich medium [86] with the following composition (in 1 liter of distilled water): $\mathrm{KH}_{2} \mathrm{PO}_{4} 0.4 \mathrm{~g} ; \mathrm{K}_{2} \mathrm{HPO}_{4} 0.6 \mathrm{~g}$; $\mathrm{NaCl} 1.1 \mathrm{~g}$; $\mathrm{NH}_{4} \mathrm{Cl} 0.5 \mathrm{~g} ; \mathrm{MgSO}_{4}$ x $7 \mathrm{H}_{2} \mathrm{O} 0.2 \mathrm{~g} ; \mathrm{CaCl}_{2} 26 \mathrm{mg} ; \mathrm{MnSO}_{4} 10 \mathrm{mg} ; \mathrm{Na}_{2} \mathrm{MoO}_{4} 2 \mathrm{mg} ;$ Fe(III)-EDTA $66 \mathrm{mg}$; yeast extract $1 \mathrm{~g}$; bactopeptone $3 \mathrm{~g}$; ethanol $6 \mathrm{ml}$ (pH 6.8). E. coli

328 strains were grown in lysogeny broth (LB) medium [87] at $37^{\circ} \mathrm{C}$. When required,

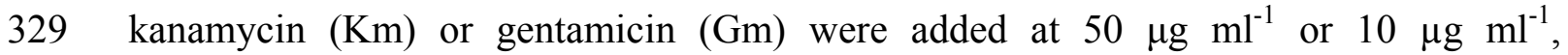
330 respectively. The growth of the cultures was monitored by measuring the absorbance at $331600 \mathrm{~nm}\left(A_{600}\right)$ using a Shimadzu UV-260 spectrophotometer or by counting viable cells.

332 Cell morphology was analyzed with a Nikon OPTIPHOT-2 phase contrast microscope.

\section{Molecular biology techniques}

335 Standard molecular biology techniques were performed as previously described [88].

336 DNA fragments were purified with Gene-Turbo (BIO101 Systems). Plasmids and PCR 337 products were purified with a High Pure Plasmid and PCR Product Purifications kits 338 (Roche), respectively. Oligonucleotides were supplied by Sigma Co and they are 339 detailed in Supplementary Table S2 in Additional file 1. All cloned inserts and DNA 340 fragments were confirmed by DNA sequencing with fluorescently labeled 341 dideoxynucleotide terminators [89] and AmpliTaq FS DNA polymerase (Applied 342 Biosystems) in an ABI Prism 377 automated DNA sequencer (Applied Biosystems). 
343 Transformations of E. coli was carried out by using the $\mathrm{RbCl}$ method or by

344 electroporation (Gene Pulser, Bio-Rad) [88]. Transformation of Azoarcus sp. CIB was

345 done by biparental conjugation using the strain E. coli S17-1 $\lambda$ pir as donor, following a

346 protocol previously established [90] with slight modifications: donor cells were grown

347 to $A_{600}$ of 5 and the receptor CIB strain was grown on MC medium supplemented with

348 pyruvate $0.2 \%$, and concentrated to reach an $A_{600}$ of 35 . The transconjugants were

349 selected on MC medium supplemented with $10 \mathrm{mM}$ glutarate plus the corresponding 350 antibiotic.

352 Construction of Azoarcus sp. CIBdpilX, Azoarcus sp. CIBdfliM and Azoarcus sp.

353 CIBdepsF mutant strains

354 For insertional disruption of pilX, fliM and epsF genes in the genome of Azoarcus sp.

355 CIB we used single homologous recombination with PCR-amplified DNA fragments

356 obtained with the primer pairs 5'pilX/3'pilX; 5'fliM/3' fliM and 5'epsF/3'epsF,

357 respectively (Supplementary Table S2 in Additional file 1). The obtained fragments

358 were double-digested with the appropriate restriction enzymes, generating the

359 pK18mobpilX, pK18mobfliM and pK18mobepsF recombinant plasmids (Table 1).

360 These plasmids were transferred from E. coli S17-1גpir (donor strain) to Azoarcus sp.

361 CIB (recipient strain) by biparental filter mating (88), and exconjugants strains

362 Azoarcus sp. CIBdpilX, Azoarcus sp. CIBdfliM and Azoarcus sp. CIBdepsF were

363 isolated on kanamycin-containing MC agar plates harboring $10 \mathrm{mM}$ glutarate as the sole

364 carbon source for counterselection of donor cells. The mutant strains were verified by

365 PCR amplification using an standard oligonucleotide (F24 or R24) flanking the multiple

366 cloning site of the plasmid and a second specific oligonucleotide external to the 
367 fragment used to perform the homologous recombination (Supplementary Table S2 in 368 Additional file 1).

369

RNA extraction and quantitative reverse transcription-PCR (qRT-PCR)

\section{1 experiments}

372 RNA was purified from bacterial cells grown up to the middle of the exponential phase

373 and resuspended in a solution containing TE buffer (Tris-HCl $10 \mathrm{mM} \mathrm{pH} \mathrm{8.0,} \mathrm{EDTA}$

$3741 \mathrm{mM}$ ) and lysozyme $50 \mathrm{mg} \mathrm{ml}^{-1}$ (Sigma). Total RNA was obtained using High Pure

RNA Isolation Kit (Roche). The DNA was removed with DNAse and Removal

376 Treatment Kit (Ambion). The concentration and purity of RNA was

377 spectrophotometrically determined at $A_{260}$ and calculating the $A_{260} / A_{280}$ ratio,

378 respectively. The cDNA was obtained by using the Transcriptor First Strand cDNA

379 Synthesis kit (Roche). Each RT reaction $(20 \mu \mathrm{l})$ contained $1 \mu \mathrm{g}$ RNA, $10 \mathrm{U}$ reverse

380 transcriptase, RNAse inhibitor $20 \mathrm{U}$, dNTPS $1 \mathrm{mM}$ and $60 \mu \mathrm{M}$ random hexamer

381 primers. The standard procedure of cDNA production includes a 10 min incubation at

$38225{ }^{\circ} \mathrm{C}$ followed by 1 cycle of $30 \mathrm{~min}$ at $55^{\circ} \mathrm{C}$ and another incubation of $5 \mathrm{~min}$ at $85{ }^{\circ} \mathrm{C}$

383 using the Mastercycler Gradient equipment (Eppendorf). Then, $1 \mu$ of the obtained 384 cDNA was used as template for the PCR. The cDNA was PCR-amplified using the 385 required oligonucleotides at final concentration of $0.5 \mu \mathrm{M}$ and $1 \mathrm{U}$ of DNA polymerase 386 I (Biotools) in a final volume of $50 \mu \mathrm{l}$. The qRT-PCR reactions were performed in a 387 LightCycle ${ }^{\circledR} 480$ II Real-Time PCR Instrument (Roche). The volume of reaction was 20 $388 \mu \mathrm{l}$ and contained $1 \mu \mathrm{l}$ cDNA, $0.25 \mu \mathrm{M}$ oligonucleotides and $10 \mu \mathrm{l}$ SYBR Green Master 389 Mix (Roche). The $d n a E$ gene was used as housekeeping control as reported before [91].

390 The results are shown as relative quantification using the $\Delta \Delta \mathrm{Ct}$ method [92]. 


\section{Inoculation of rice seedlings with bacteria}

393 Dehulled rice seeds (O. sativa L. GLEVA) were surface sterilized by shaking them at 25

$394{ }^{\circ} \mathrm{C}$ for $30 \mathrm{~min}$ in $30 \mathrm{ml} 1 \%(\mathrm{v} / \mathrm{v})$ sodium hypochlorite. After rinsing them three times for

$39510 \mathrm{~min}$ in sterile water, the seeds were incubated in VM-ethanol for $48 \mathrm{~h}$. The germ-free

396 seedlings were selected for inoculation. The germination of the seeds continued on

397 humidified filter papers for $24 \mathrm{~h}$ prior to inoculation with bacterial cells. Bacteria were

398 obtained as described previously [53]. After growth up to mid-exponential phase,

399 bacterial cells were collected by centrifugation, washed with sterile $0.9 \% \mathrm{NaCl}(\mathrm{w} / \mathrm{v})$

400 solution, resuspended in $1 \mathrm{ml}$ of sterile distilled water, and the cell suspension was

401 inoculated onto the surface of each seedling in aseptic conditions. After inoculation, the

402 seedlings were grown at $25{ }^{\circ} \mathrm{C}$ under natural daylight conditions $(10 \mathrm{~h}$ of light and $14 \mathrm{~h}$

403 of darkness) for 5-10 days.

404

405 Recovery and quantification of endophytes

406 Rice seedlings were collected 5 days after inoculation with bacterial strains. The roots

407 were weighed, proceeding to its surface disinfection by immersion for 3 minutes in a

$4081 \%(\mathrm{v} / \mathrm{v})$ solution of sodium hypochlorite and three washes with sterile water. The roots 409 were then homogenized by adding $1 \mathrm{ml}$ of saline $(0.85 \% \mathrm{NaCl})$ solution to a Potter-

410 Elvehjem [93]. Once the extract was obtained, serial dilutions were made and plated in

411 VM medium plates (1.5\% agar) supplemented with kanamycin in order to determine the 412 number of CFUs.

413

414 Motility tests

415 Swimming-type motility assays were performed on semi-solid VM-agar $0.3 \%$ medium

416 plates using cultures grown in VM-ethanol liquid medium up to an $A_{600}$ of 0.6. For 
417 swarming motility assays, plates of MC medium with $0.2 \%$ pyruvate $(\mathrm{w} / \mathrm{v})$ and semi-

418 solid $0.4 \%$ agar were used employing cultures grown in liquid MC medium with $0.2 \%$

419 pyruvate (w/v) up to an $A_{600}$ of 0.6 . The plates were incubated for 7 days at $30^{\circ} \mathrm{C}$ and

420 the diameter of the growth halos of the different Azoarcus sp. CIB strains was

421 measured.

422

423 Colony morphology

424 The morphological study of the colonies of Azoarcus sp. CIB strains was performed on

425 VM medium plates supplemented with $0.5 \mathrm{~g} \mathrm{l}^{-1}$ of Congo Red dye (Sigma-Aldrich). The

426 bacteria were grown in VM-ethanol liquid medium up to an $A_{600}$ of 0.6. Subsequently,

427 serial dilutions were made in saline solution $(0.85 \% \mathrm{NaCl})$ and plated on $\mathrm{VM}$-Congo

428 Red plates. The plates were incubated for 7 days at $30{ }^{\circ} \mathrm{C}$ and the morphology of

429 isolated colonies was analyzed with a Leica MZ16FA stereomicroscope.

430

431 Sequence Data Analyses

432 Nucleotide sequence analyses were done at the National Center for Biotechnology

433 Information (NCBI) server (https://www.ncbi.nlm.nih.gov/).

434

435 Statistical analysis

436 The data were analysed with the program IBM SPSS statistics 24 using One-way 437 analysis of the variance (One-way ANOVA) to determine significant differences 438 between the mean obtained in the assays performed. The post hoc Bonferroni test was 439 employed to compare the different conditions. Statistical differences were presented as 440 $p<0.001\left({ }^{* * *}\right), p<0.01(* *)$ or $p<0.05\left(^{*}\right)$. 
442 Supplementary information

443 Additional file 1. Includes all Supplementary Tables.

444

445 Acknowledgements

446 We thank A. Valencia for technical assistance and Secugen S.L. for DNA sequencing.

447

448 Authors contribution

449 H.F.Ll. performed the experiments and participate in data analyses. E.D. and M.C.

450 wrote the manuscript and collaborate in data analyses. All authors discussed and 451 reviewed the manuscript. The authors read and approved the final manuscript.

452

453 Funding

454 This work was supported by grants BIO2016-79736-R, PCIN-2014-113, and PCI2019-

455 111833-2 from the Ministry of Economy and Competitiveness of Spain; by Grant CSIC 45620172 0I 015; and by European Union H2020 Grant 760994.

457

458 Availability of data and materials

459 Azoarcus sp. strain CIB was deposited in the Spanish Type Culture Collection (CECT

460 \#5669). Seeds from Oryza sativa L. GLEVA were kindly provided by Castells Seeds 461 Co. (Spain).

462

463 Ethics approval and consent to participate

464 Not applicable.

465

466 Consent for publication 
Not applicable.

468

469

\section{Competing interests}

470

The authors declare that they have no competing interests.

471

472 Figure legends

473

474 Fig. 1. Swimming and rice colonization phenotypes of the Azoarcus sp. CIB and 475 Azoarcus sp. CIBdfliM strains. a Swimming motility of the Azoarcus sp. CIB (carrying 476 the control plasmid pSEVA237) and Azoarcus sp. CIBdfliM strains, and quantification 477 of the diameter of the halos $(n=3)$; the error bars indicate the standard deviation. $\mathbf{b}$ 478 Quantification of the number of endophytes recovered from rice roots after inoculation with Azoarcus sp. CIB (pSEVA237) and Azoarcus sp. CIBdfliM strains. Graph shows the CFU values per gram of root (fresh weight) from three independent experiments \pm standard deviation. The asterisks show the significance of the differences observed 482 when comparing the two strains and applying the statistical method of analysis of variance ANOVA and Bonferroni test $p<0.01(* *) ; p<0.05\left(^{*}\right)$.

Fig. 2. Motility and rice colonization phenotypes of the Azoarcus sp. CIB and Azoarcus 486 sp. CIBdpilX strains. a Swarming motility of Azoarcus sp. CIB (carrying the control 487 plasmid pSEVA237) (left) and Azoarcus sp. CIBdpilX (right), and quantification of the 488 diameter of the halos $(n=3)$; the error bars indicate the standard deviation. b 489 Quantification of the number of endophytes recovered from rice roots after inoculation 490 of rice seedlings with the Azoarcus sp. CIB (pSEVA237) and Azoarcus sp. CIBdpilX. 491 The graph shows the CFU values per gram of root (fresh weight) of three independent 
experiments; error bars indicate standard deviation. Asterisks show the significance of

493 the differences observed when comparing the two strains and applying the statistical

494 method of ANOVA analysis of variance and Bonferroni test $p<0.01(* *) ; p<0.05\left(^{*}\right)$.

495

496 Fig. 3. Colony morphology and rice colonization capacity of the Azoarcus sp. CIB and

497 Azoarcus sp. CIBdepsF strains. a Morphology of the colonies of Azoarcus sp. CIB

498 (pSEVA237) and Azoarcus sp. CIBdepsF strain grown in VM solid medium

499 supplemented with Congo red $\left(0.5 \mathrm{~g} \mathrm{l}^{-1}\right)$. The colonies were visualized with a Leica

500 MZ16FA stereomicroscope. b Quantification of the number of endophytes recovered

501 from rice roots after inoculation with Azoarcus sp. CIB (pSEVA237) and Azoarcus sp.

502 CIBdeps $F$ strains. Graph shows the CFU values per gram of root (fresh weight) of three

503 independent experiments \pm standard deviation. The asterisk shows the significance of

504 the differences observed when comparing the two situations and applying the statistical

505 method of ANOVA analysis of variance and Bonferroni test $p<0.05\left(^{*}\right)$.

506

507 Fig. 4. Motility and morphology of the colonies of Azoarcus sp. CIB strains expressing 508 genes involved in the metabolism of c-di-GMP. The plates were inoculated with 509 Azoarcus sp. CIB (pIZ1016) (empty plasmid), Azoarcus sp. CIB (pIZ2133) (expressing 510 the PA2133 phosphodiesterase) and Azoarcus sp. CIB (pIZ4959) (expressing the 511 PP4959 diguanylate cyclase).

512

513 Fig. 5. Rice roots colonization by Azoarcus sp. CIB strains producing different levels of 514 c-di-GMP. Rice seedlings were inoculated with Azoarcus sp. CIB (pIZ1016) (empty 515 plasmid), Azoarcus sp. CIB (pIZ2133) (expressing the PA2133 phosphodiesterase) and

516 Azoarcus sp. CIB (pIZ4959) (expressing the PP4959 diguanylate cyclase). Plants were 
517 grown at $25{ }^{\circ} \mathrm{C}$ for 5 days and bacteria present inside the roots were determined as

518 described in Methods. The graph shows the CFU values per gram of root (fresh weight)

519 of three independent experiments; error bars represent the standard deviation. Asterisks

520 show the significance of the differences observed when comparing the strains with

521 modified levels of c-di-GMP with respect to the control strain and applying the

522 statistical method of ANOVA analysis of variance and Bonferroni test $p<0.01(* *) ; p$

$523<0.05(*)$.

524

525 Fig. 6. Expression of the pilY1, fliC and epsF genes in Azoarcus sp. CIB strains 526 producing different levels of c-di-GMP. The transcript levels of the pilY1, fliC and epsF 527 genes in the Azoarcus sp. CIB (pIZ2133) (black columns) and Azoarcus sp. CIB 528 (pIZ4959) (white columns) strains grown in VM-ethanol medium for $24 \mathrm{~h}$, were determined by quantitative RT-PCR using dnaE gene as internal control, as detailed in Methods. The expression of the genes in each strain is shown relative to their expression

531 in the control strain Azoarcus sp. CIB (pIZ1016). The mean value and the standard 532 deviation corresponding to the results of three independent experiments are indicated.

533 Asterisks show the significance of the differences observed when comparing the level of expression of modified strains with respect to wild-type strain applying the statistical method of ANOVA analysis of variance and Bonferroni test $p<0.01$.

537 References

539 1. Bulgarelli D, Schlaeppi K, Spaepen S, van Themaat EVL, Schulze-Lefert P. Structure 540 and functions of the bacterial microbiota of plants. Annu Rev Plant Biol. 2013;64:80754138. 
543 2. Reinhold-Hurek B, Bünger W, Burbano CS, Sabale M, Hurek T. Roots shaping their

544 microbiome: global hotspots for microbial activity. Annu Rev Phytopathol. $545 \quad 2015 ; 53: 403-24$.

546

547 3. Gopal M, Gupta A. Microbiome selection could spur next-generation plant breeding 548 strategies. Front Microbiol. 2016;7:1971.

549

550 4. Shidore T, Dinse T, Öhrlein J, Becker A, Reinhold-Hurek B. Transcriptomic analysis 551 of responses to exudates reveal genes required for rhizosphere competence of the 552 endophyte Azoarcus sp. strain BH72. Environ Microbiol. 2012;14:2775-87.

553

554 5. Alquéres S, Meneses C, Rouws L, Rothballer M, Baldani I, Schmid M, et al. The 555 bacterial superoxide dismutase and glutathione reductase are crucial for endophytic

556 colonization of rice roots by Gluconacetobacter diazotrophicus PAL5. Mol Plant 557 Microbe Interact. 2013;26:937-45.

558

559 6. Drogue B, Sanguin H, Borland S, Prigent-Combaret C, Wisniewski-Dyé F. Genome 560 wide profiling of Azospirillum lipoferum 4B gene expression during interaction with 561 rice roots. FEMS Microbiol Ecol. 2014;87:543-55.

562

563 7. Kaul S, Sharma T, Dhar MK. "Omics" tools for better understanding the plant564 endophyte interactions. Front Plant Sci. 2016;7:955. 
566 8. Hardoim PR, van Overbeek LS, van Elsas JD. Properties of bacterial endophytes and

567 their proposed role in plant growth. Trends Microbiol. 2008;16:463-71.

568

569 9. Hardoim PR, van Overbeek LS, Berg G, Pirttilä AM, Compant S, Campisano A, et 570 al. The hidden world within plants: ecological and evolutionary considerations for 571 defining functioning of microbial endophytes. Microbiol Mol Biol Rev. 2015,79:293572320.

573

574 10. Reinhold-Hurek B, Hurek T. Living inside plants: bacterial endophytes. Curr Opin 575 Plant Biol. 2011,14:435-43.

576

577 11. Mitter B, Petric A, Shin MW, Chain PSG, Hauberg-Lotte L, Reinhold-Hurek B, et 578 al. Comparative genome analysis of Burkholderia phytofirmans PsJN reveals a wide spectrum of endophytic lifestyles based on interaction strategies with host plants. Front

$580 \quad$ Plant Sci. 2013;4:120.

581

582 12. Newman MA, Sundelin T, Nielsen JT, Erbs G. MAMP (microbe-associated 583 molecular pattern) triggered immunity in plants. Front Plant Sci. 2013;4:139.

584

585 13. Buschart A, Sachs S, Chen X, Herglotz J, Krause A, Reinhold-Hurek B. Flagella 586 mediate endophytic competence rather than act as MAMPS in rice-Azoarcus sp. strain 587 BH72 interactions. Mol Plant Microbe Interact. 2012;25:191-9. 
590 profiling of the endophyte Burkholderia phytofirmans PsJN indicates sensing of the 591 plant environment and drought stress. mBio 2015;6:1-11.

592

593 15. Böhm M, Hurek T, Reinhold-Hurek B. Twitching motility is essential for 594 endophytic rice colonization by the $\mathrm{N}_{2}$-fixing endophyte Azoarcus sp. strain BH72. Mol 595 Plant-Microbe Interact. 2007;20:526-33.

596

16. James EK, Gyaneshwar P, Mathan N, Barraquio WL, Reddy PM, Iannetta PPM, et 598 al.. Infection and colonization of rice seedlings by the plant growth-promoting 599 bacterium Herbaspirillum seropedicae Z67. Mol Plant-Microbe Interact. 2002;15:894600906.

601

17. Danhorn T. Fuqua C. Biofilm formation by plant-associated bacteria. Annu Rev 603 Microbiol. 2007;61:401-22.

604

605

18. Compant S, Kaplan H, Sessitsch A, Nowak J, Ait Barka E, Clément C. Endophytic 606 colonization of Vitis vinifera L. by Burkholderia phytofirmans strain PsJN: from the 607 rhizosphere to inflorescence tissues. FEMS Microbiol Ecol. 2008;63:84-93.

608

609 19. Balsanelli E, Tuleski TR, de Baura VA, Yates MG, Chubatsu LS, de Oliveira 610 Pedrosa F, et al. Maize root lectins mediate the interaction with Herbaspirillum 611 seropedicae via N-acetyl glucosamine residues of lipopolysaccharides. PLoS One 2013; $6128: \mathrm{e} 77001$ 
614 20. Meneses CHSG, Rouws LFM, Simoes-Araujo JL, Vidal MS, Baldani JI.

615 Exopolysaccharide production is required for biofilm formation and plant colonization

616 by the nitrogen-fixing endophyte Gluconacetobacter diazotrophicus. Mol Plant Microbe

617 Interact. 2011;24:1448-58.

618

619 21. Schmid J, Sieber V, Rehm B. Bacterial exopolysaccharides: biosynthesis pathways 620 and engineering strategies. Front Microbiol. 2015;6:496.

621

622 22. Janczarek M, Rachwał K, Cieśla J, Ginalska G, Bieganowski A. Production of 623 exopolysaccharide by Rhizobium leguminosarum bv. trifolii and its role in bacterial 624 attachment and surface properties. Plant Soil. 2015;388:211-27.

625

626

23. Nian HJ, Zhang J, Liu S, Song FP, Huang DF. Effect of bacteriaphage and exopolysaccharide on root colonization and rhizosphere competence by Pseudomonas 628 fluorescens. Ann Microbiol. 2010;60:369-72.

629

630 24. Römling U, Galperin MY, Gomelsky M. Cyclic di-GMP: the first 25 years of a 631 universal bacterial second messenger. Microbiol Mol Biol Rev. 2013;77:1-52.

632

633 25. Jenal U, Reinders A, Lori C. Cyclic di-GMP: second messenger extraordinaire. Nat 634 Rev Microbiol. 2017;15:271-84.

635

636 26. Hickman JW, Tifrea DF, Harwood CS. A chemosensory system that regulates 637 biofilm formation through modulation of cyclic diguanylate levels. Proc Natl Acad Sci $638 \quad$ USA. 2005;102:14422-27. 
640 27. Lee VT, Matewish JM, Kessler JL, Hyodo M, Hayakawa Y, Lory S. A cyclic-di-

641 GMP receptor required for bacterial exopolysaccharide production. Mol Microbiol. $642 \quad 2007 ; 65: 1474-84$.

643

644 28. Borlee BR, Goldman AD, Murakami K, Samudrala R, Wozniak DJ, Parsek MR. 645 Pseudomonas aeruginosa uses a cyclic di-GMP-regulated adhesin to reinforce the 646 biofilm extracellular matrix. Mol Microbiol. 2010;75:827-42.

647

648

29. Liang ZX. The expanding roles of c-di-GMP in the biosynthesis of 649 exopolysaccharides and secondary metabolites. Nat Prod Rep. 2015;32:663-83.

650

651

30. Schäper S, Krol E, Skotnicka D, Kaever V, Hilker R, Sǿgarrd-Andersen L, et al. 652 Cyclic di-GMP regulates multiple cellular functions in the symbiotic alphaproteobacterium Sinorhizobium meliloti. J Bacteriol. 2015;198:521-35.

654

655

31. Simm R, Morr M, Kader A, Nimtz M, Römling U. GGDEF and EAL domains 656 inversely regulate cyclic di-GMP levels and transition from sessility to motility. Mol Microbiol. 2004;53:1123-34.

658

659 32. Starkey M, Hickman JH, Ma L, Zhang N, De Long S, Hinz A, et al. Pseudomonas 660 aeruginosa rugose small-colony variants have adaptations that likely promote 661 persistence in the cystic fibrosis lung. J Bacteriol. 2009,191:3492-503.

662 
663 33. Waters CM, Lu W, Rabinowitz JD, Bassler BL. Quorum sensing controls biofilm 664 formation in Vibrio cholerae through modulation of cyclic di-GMP levels and 665 repression of vpsT. J Bacteriol. 2008;190:2527-36.

666

667 34. Kazmierczak BI, Lebron MB, Murray TS Analysis of FimX, a phosphodiesterase 668 that governs twitching motility in Pseudomonas aeruginosa. Mol Microbiol. $6692006 ; 60: 1026-43$.

670

671 35. Wolfe AJ, Visick KL. Get the message out: cyclic-di-GMP regulates multiple levels 672 of flagellum-based motility. J Bacteriol. 2008;190:463-75.

673

674 36. McCarter LL, Gomelsky M. Fifty ways to inhibit motility via cyclic di-GMP: the 675 emerging Pseudomonas aeruginosa swarming story. J Bacteriol. 2015;197:406-9.

676

677

37. Skotnicka D, Petters T, Heering J, Hoppert M, Kaever V, Sogaard-Andersen L. c-di678 GMP regulates type IV pili-dependent-motility in Myxococcus xanthus. J Bacteriol. $6792015 ; 198: 77-90$.

680

681

38. Sun Y, Xie Z, Sui F, Liu X, Cheng W. Identification of Cbp1, a c-di-GMP binding 682 chemoreceptor in Azorhizobium caulinodans ORS571 involved in chemotaxis and 683 nodulation of the host plant. Front Microbiol. 2019;10:638.

684

685

39. Tischler AD, Camilli A. Cyclic diguanylate regulates Vibrio cholerae virulence 686 gene expression. Infect Immun. 2005;73:5873-82.

687 
40. Ryan RP. Cyclic di-GMP signalling and the regulation of bacterial virulence.

689 Microbiology. 2013;159:1286-97.

690

691 41. Martinez-Gil M, Ramos C. Role of cyclic di-GMP in the bacterial virulence and 692 evasion of the plant immunity. Curr Issues Mol Biol. 2018;25:199-222.

693

694 42. Pérez-Mendoza D, Aragón IM, Prada-Ramírez HA, Romero-Jiménez L, Ramos C, 695 Gallegos MT, et al. Responses to elevated c-di-GMP levels in mutualistic and 696 pathogenic plant-interacting bacteria. PLoS One. 2014;9:e91645.

697

698

699

43. Aragón IM, Pérez-Mendoza

D, Gallegos MT, Ramos

C. The c-di-GMP phosphodiesterase BifA is involved in the virulence of bacteria from the Pseudomonas 700 syringae complex. Mol Plant Pathol. 2015;16:604-15.

701

702

44. McCarthy Y, Ryan RP, O’Donovan K, He YQ, Jiang BL, Feng JX, et al. The role of 703 PilZ domain proteins in the virulence of Xanthomonas campestris pv. campestris. Mol Plant Pathol. 2008;9:819-24.

705

706

45. Ryan RP, McCarthy Y, Andrade M, Farah CS, Armitage JP, Dow JM. Cell-cell

707 signal-dependent dynamic interactions between HD-GYP and GGDEF domain proteins

708 mediate virulence in Xanthomonas campestris. Proc Natl Acad Sci USA. $7092010 ; 107: 5989-94$. 
711 46. An SQ, Allan JH, McCarthy Y, Febrer M, Dow JM, Ryan RP. The PAS domain-

712 containing histidine kinase RpfS is a second sensor for the diffusible signal factor of

713 Xanthomonas campestris. Mol Microbiol. 2014;92:586-97.

714

715 47. Zhang Y, Wei C, Jiang,W, Wang L, Li C, Wang Y, et al. The HD-GYP domain

716 protein RpfG of Xanthomonas oryzae pv. oryzicola regulates synthesis of extracellular

717 polysaccharides that contribute to biofilm formation and virulence on rice. PLoS One.

$718 \quad 2013 ; 8: \mathrm{e} 59428$.

719

720 48. Yang F, Tian F, Li X, Fan S, Chen H, Wu M, et al. The degenerate EAL-GGDEF

721 domain protein filp functions as a cyclic di-GMP receptor and specifically interacts with

722 the PilZ-domain protein PXO_02715 to regulate virulence in Xanthomonas oryzae pv. oryzae. Mol Plant-Microbe Interact. 2014;27:578-89.

724

725

49. Gao S, Romdhane SB, Beullens S, Kaever V, Lambrichts I, Fauvart M, et al.

726 Genomic analysis of cyclic-di-GMP-related genes in rhizobial type strains and

727 functional analysis in Rhizobium etli. Appl Microbiol Biotechnol. 2014,98:4589-602.

728

729

50. Lim B, Beyhan S, Meir J, Yildiz FH. Cyclic-diGMP signal transduction systems in

Vibrio cholerae: Modulation of rugosity and biofilm formation. Mol Microbiol. 2006;60:331-48.

732

733 51. Ryan RP, Fouhy Y, Lucey JF, Dow JM. Cyclic di-GMP signaling in bacteria:

734 Recent advances and new puzzles. J Bacteriol. 2006;188:8327-34. 
737 EAL domain is required for negative regulation of biofilm formation in Yersinia pestis. FEMS Microbiol Lett. 2005;247:123-30.

739

740 53. Fernández-Llamosas H, Prandoni N, Fernández-Pascual M, Fajardo S, Morcillo C,

741 Díaz E, et al. Azoarcus sp. CIB, an anaerobic biodegrader of aromatic compounds

742 shows an endophytic lifestyle. PLoS One. 2014;9:e110771.

743

744 54. Fernández-Llamosas, H: Adaptación de Azoarcus sp. CIB a diferentes condiciones 745 ambientales. PhD thesis. Complutense University of Madrid, Madrid, Spain. 2018.

55. Martín-Moldes Z, Zamarro MT, del Cerro C, Valencia A, Gómez MJ, Arcas A, et al. Whole-genome analysis of Azoarcus sp. strain CIB provides genetic insights to its different lifestyles and predicts novel metabolic features. Syst Appl Microbiol. 2015;38:462-71.

751

752

56. López-Barragán MJ, Carmona M, Zamarro MT, Thiele M, Boll M, Fuchs G, et al. The bzd gene cluster, coding for anaerobic benzoate catabolism in Azoarcus sp. CIB. J Bacteriol. 2004;186:5462-74.

57. Blázquez B, Carmona M, Díaz E. Transcriptional regulation of the peripheral 757 pathway for the anaerobic catabolism of toluene and $m$-xylene in Azoarcus sp. CIB. 758 Front Microbiol. 2018;9:506. 

of selenium nanoparticles by Azoarcus sp. CIB. Microb Cell Fact. 2017;15:109.

59. Durante-Rodríguez G, Fernández-Llamosas H, Alonso-Fernandes E, Fernández-

Muñiz MN, Muñoz-Olivas R, Díaz E, et al. ArxA from Azoarcus sp. CIB, an anaerobic arsenite oxidase from an obligate heterotrophic and mesophilic bacterium. Front Microbiol. 2019;10:1699.

767

60. Rabus R, Wöhlbrand L, Thies D, Meyer M, Reinhold-Hurek B, Kämpfer P. Aromatoleum gen. nov., a novel genus accommodating the phylogenetic lineage including Azoarcus evansii and related species, and proposal of Aromatoleum aromaticum sp. nov., Aromatoleum petrolei sp. nov., Aromatoleum bremense sp. nov., Aromatoleum toluolicum sp. nov. and Aromatoleum diolicum sp. nov. Int J Syst Evol Microbiol. 2019;69:982-97.

61. Marykwas DL, Berg HC. A mutational analysis of the interaction between FliG and FliM, two components of the flagellar motor of Escherichia coli. J Bacteriol. 1996; 178:1289-94.

62. Paul K, Nieto V, Carlquist,WC, Blair DF, Harshey RM. The c-di-GMP binding

780 protein YcgR controls flagellar motor direction and speed to affect chemotaxis by a 781 "backstop brake” mechanism. Mol Cell. 2010;38:128-39.

783 63. Morimoto Y, Minamino, T. Structure and function of the bi-directional bacterial 784 flagellar motor. Biomolecules. 2014;4:217-34. 
786 64. Kojima S, Blair DF The bacterial flagellar motor: structure and function of a 787 complex molecular machine. Int Rev Cytol. 2004;233:93-134.

788

789 65. Anyan ME, Amiri A, Harvey CW, Tierra G, Morales-Soto N, Driscoll CM, et al. 790 Type IV pili interactions promote intercellular association and moderate swarming of 791 Pseudomonas aeruginosa. Proc Natl Acad Sci USA. 2014;111:18013-18.

792

793

66. Köhler T, Curty LK, Barja F, van Delden C, Pechère JC. Swarming of 794 Pseudomonas aeruginosa is dependent on cell-to-cell signaling and requires flagella 795 and pili. J Bacteriol. 2000;182:5990-96.

796

797 67. Kuchma SL, Griffin EF, O'Toole GA. Minor pilins of the type IV pilus system 798 participate in the negative regulation of swarming motility. J Bacteriol. 2012;194:5388799 403.

800

801

68. Dörr J, Hurek T, Reinhold-Hurek B. Type IV pili are involved in plant-microbe and 802 fungus-microbe interactions. Mol Microbiol. 1998;30: 7-17.

803

804 69. Giltner CL, Nguyen Y, Burrows LL. Type IV pilin proteins: versatile molecular 805 modules. Microbiol Mol Biol Rev. 2012;76:740-72.

806

807 70. Chung JW, Altman E, Beveridge TJ, Speert DP. Colonial morphology of 808 Burkholderia cepacia complex genomovar III: implications in exopolysaccharide 
809 production, pilus expression, and persistence in the mouse. Infect Immun. 2003;71: 904-

8109.

811

812 71. Sousa AM, Machado I, Nicolau A, Pereira, MO. Improvements on colony

813 morphology identification towards bacterial profiling. J.Microbiol Methods.

$814 \quad 2013 ; 95: 327-35$

815

816 72. Bordeleau E, Purcell EB, Lafontaine DA, Fortier L-C, Tamayo R, Burrus V. Cyclic

817 di-GMP riboswitch-regulated type IV pili contribute to aggregation of Clostridium

818 difficile. J Bacteriol. 2015;197:819-32.

819

820 73. Schmid J., Rühmann B, Sieber V, Romero-Jiménez L, Sanjuán J, Pérez-Mendoza D.

821 Screening of c-di-GMP-regulated exopolysaccharides in host interacting bacteria. In

822 Medina C, López-Baena F., editors. Host-Pathogen Interactions. Methods in Molecular

823 Biology, vol 1734. New York; Humana Press,; 2018.

824

825 74. Baker AE, Webster SS, Diepold A, Kuchma SL, Bordeleau E, Armitage JP, et al.

826 Flagellar stators stimulate c-di-GMP production by Pseudomonas aeruginosa. J

827 Bacteriol. 2019;201:e00741-18.

828

829 75. Matilla MA, Travieso ML, Ramos JL, Ramos-González MI. 2011. Cyclic

830 diguanylate turnover mediated by the sole GGDEF/EAL response regulator in

831 Pseudomonas putida: its role in the rhizosphere and an analysis of its target processes.

832 Environ Microbiol 13:1745-1766.

833 
834 76. Martín-Moldes Z, Blázquez B, Baraquet C, Harwood CS, Zamarro MT, Díaz E.

835 Degradation of cyclic diguanosine monophosphate by a hybrid two-component protein

836 protects Azoarcus sp. strain CIB from toluene toxicity. Proc Natl Acad Sci USA.

$837 \quad 2016 ; 113: 13174-79$.

838

839 77. Kandel S L, Joubert PM, Doty SL. Bacterial endophyte colonization and distribution

840 within plants. Microorganisms. 2017;5:77.

841

842 78. Pérez-Mendoza D, Sanjuán J. Exploiting the commons: cyclic diguanylate

843 regulation of bacterial exopolysaccharide production. Curr Opin Microbiol. 2016;30:36-

84443.

845

846 79. Lin Chua S, Liu Y, Li Y, Jun Ting H, Kohli GS, Cai Z, Suwanchaikasem P, et al.

847 Reduced intracellular c-di-GMP content increases expression of quorum sensing-

848 regulated genes in Pseudomonas aeruginosa. Front Cell Infect Microbio. 2017;7:451.

849

850 80. Beyhan S, Tischler AD, Camilli A, Yildiz FH. Transcriptome and phenotypic 851 responses of Vibrio cholerae to increased cyclic di-GMP level. J Bacteriol. 2006, $852 \quad 188: 3600-13$.

853

854 81. Srivastava D, Harris RC, Waters CM. Integration of cyclic di-GMP and quorum 855 sensing in the control of vpsT and aphA in Vibrio cholerae. J Bacteriol. 2011;193:633185641. 

as a c-di-GMP-responsive transcription factor. Mol Microbiol. 2008;69:376-89.

860

83. Molina-Henares MA, Ramos-González MI, Daddaoua A, Fernández-Escamilla AM,

862 Espinosa-Urgel M. FleQ of Pseudomonas putida KT2440 is a multimeric cyclic 863 diguanylate binding protein that differentially regulates expression of biofilm matrix components. Res Microbiol. 2017;168:36-45.

865

866

84. Pitzer JE, Sultan SZ, Hayakawa Y, Hobbs G, Miller MR, Motaleb MA. Analysis of

867 the Borrelia burgdorferi cyclic-di-GMP-binding protein PlzA reveals a role in motility 868 and virulence. Infect Immun. 2011;79:1815-25.

869

870 85. Russell MH, Bible AN, Fang X, Gooding JR, Campagna SR, Gomelsky M, et al..

871 Integration of the second messenger c-di-GMP into the chemotactic signaling pathway.

872 MBio. 2013;4:e00001-13.

873

874 86. Reinhold-Hurek B, Hurek T, Gillis M, Hoste B, Vancanneyt M, Kersters K, et al. 875 Azoarcus gen. nov., nitrogen-fixing proteobacteria associated with roots of Kallar grass

876 (Leptochloa fusca (L.) Kunth), and description of two species, Azoarcus indigens sp.

877 nov. and Azoarcus communis sp. nov. Int J Syst Bacteriol. 1993;43:574-84.

878

879 87. Miller JH. Experiments in molecular genetics. New York: Cold Spring Harbor 880 Laboratory Press; 1972. 
882 88. Sambrook J, Rusell D. Molecular cloning: a laboratory manual. New York: Cold 883 Spring Harbor Laboratory Press. New York; 2001.

884

885 89. Sanger F, Nicklen S, Coulson AR. DNA sequencing with chain-terminating 886 inhibitors. Proc Natl Acad Sci USA. 1977;74:5463-67.

887

888 90. De Lorenzo V, Timmis KN. Analysis and construction of stable phenotypes in 889 Gram-negative bacteria with Tn5- and Tn10-derived minitransposons. Methods $890 \quad$ Enzymol. 1994;235:386-405.

891

892 91. Valderrama JA, Durante-Rodríguez G, Blázquez B, García JL, Carmona M, Díaz E. 893 Bacterial degradation of benzoate: cross-regulation between aerobic and anaerobic 894 pathways. J Biol Chem. 2012;287:10494-508.

895

896 92. Livak KJ, Schmittgen TD. Analysis of relative gene expression data using real-time 897 quantitative PCR and the 2- $\Delta \Delta \mathrm{CT}$ Method. Methods. 2001;25:402-8.

898

899 93. Gyaneshwar P, James EK, Mathan N, Reddy PM, Reinhold-Hurek B, Ladha JK. 900 Endophytic colonization of rice by a diazotrophic strain of Serratia marcescens. J $901 \quad$ Bacteriol. 2001;183:2634-45.

902

903 94. Manoil C, Beckwith J. TnphoA: a transposon probe for protein export signals. Proc 904 Natl Acad Sci USA. 1985;82:8129-33.

905 
906 95. Silva-Rocha R, Martínez-García E, Calles B, Chavarría M, Arce-Rodríguez A, de 907 las Heras, A., et al. The standard european vector architecture (SEVA): a coherent 908 platform for the analysis and development of complex prokaryotic phenotypes. Nucl Ac 909 Res. 2013,41:D666-D675.

910

911 96. Moreno-Ruiz E, Hernáez MJ, Martínez-Pérez O., Santero E. Identification and

912 functional characterization of Sphingomonas macrogolitabida strain TFA genes

913 involved in the first two steps of the tetralin catabolic pathway. J Bacteriol. $914 \quad 2003 ; 185: 2026-30$.

915

916 97. Schäfer A, Tauch A, Jäger W, Kalinowski J, Thierbach G, Pühler A. Small 917 mobilizable multi-purpose cloning vectors derived from the Escherichia coli plasmids 918 pK18 and pK19: selection of defined deletions in the chromosome of Corynebacterium 919 glutamicum. Gene. 1994;145:69-73.

920

921

922

923

924

925 
Table 1. Bacterial strains and plasmids used in this study

\section{E. coli strains}

931

932

DH10B

933

934

935

936

937

938

939

940

941

\section{Azoarcus strains}

943 CIB

944 CIBdpilX

945 CIBd fliM

946 CIBdeps $F$

947

\section{Plasmids}

949

950

951

952

953

954

955

956

957

958

959

960

961

962

963

964

965

966

967

968

969

970

pSEVA237

pIZ1016

pIZ2133

pIZ4959

pK18mob

pK18mobpilX

pK18mobfliM

pK18mobeps $F$
F', $m c r A, \Delta(m r r h s d R M S-m c r B C)$,

Ф80lacZ4M15, AlacX74, deoR, recA1, araD139, 4 (ara-leu)7697, galU, galK, rpsL $\left(\mathrm{Sm}^{\mathrm{r}}\right)$, endAl, nupG

$\mathrm{Tp}^{\mathrm{r}} \mathrm{Sm}^{\mathrm{r}}$ recA thi hsdRM $\mathrm{RP} 4:: 2-\mathrm{Tc}:: \mathrm{Mu}:: \mathrm{Km}$

$\lambda$ pir phage lysogen

$\triangle($ ara-leu), araD, $\triangle l a c X 7$, galE, galK,

phoA20, rpoB, thi-1, rpsE, $\left(\mathrm{Sp}^{\mathrm{r}}\right)$, (Rf'),

$\operatorname{argE},(\mathrm{Am}), \operatorname{rec} A 1$

Wild type strain

$\mathrm{Km}^{\mathrm{R}}$, CIB mutant by insertion in the pilX gene

$\mathrm{Km}^{\mathrm{R}}$, CIB mutant by insertion in the fliM gene

$\mathrm{Km}^{\mathrm{R}}$, CIB mutant by insertion in the eps $F$ gene

$\mathrm{Km}^{\mathrm{r}}$, ori $\mathrm{pBBR} 1$, harbors the $g f p$ gene under the control of the PlexA promoter

$\mathrm{Gm}^{\mathrm{r}}$, ori pBBR1MCS-5 derivative vector for cloning and expression harboring the Ptac promoter and the lacI gene

$\mathrm{Gm}^{\mathrm{R}}$, pIZ1016 derivative containing the gene

PA2133 from $P$. aeruginosa PAO1 under the control of the Ptac promoter

$\mathrm{Gm}^{\mathrm{R}}$, pIZ1016 derivative containing the gene PP4959 from $P$. putida KT2440 under the control of the Ptac promoter $\mathrm{Km}^{\mathrm{R}}$, oriColE1, $\mathrm{Mob}^{+}$, lacZ $\alpha$, suicide vector for the construction of insertion mutants by homologous recombination

$\mathrm{Km}^{\mathrm{R}}$, pK18mob derivative that includes a 455 bp pilX HindIII/BamHI internal fragment $\mathrm{Km}^{\mathrm{R}}$, pK18mob derivative that includes a 512 bp fliM HindIII/BamHI internal fragment $\mathrm{Km}^{\mathrm{R}}$, pK18mob derivative that includes a 635 bp epsF HindIII/BamHI internal fragment
Life Technologies

[56]

This work

This work

This work

This work

This work

This work 


\section{Figures}
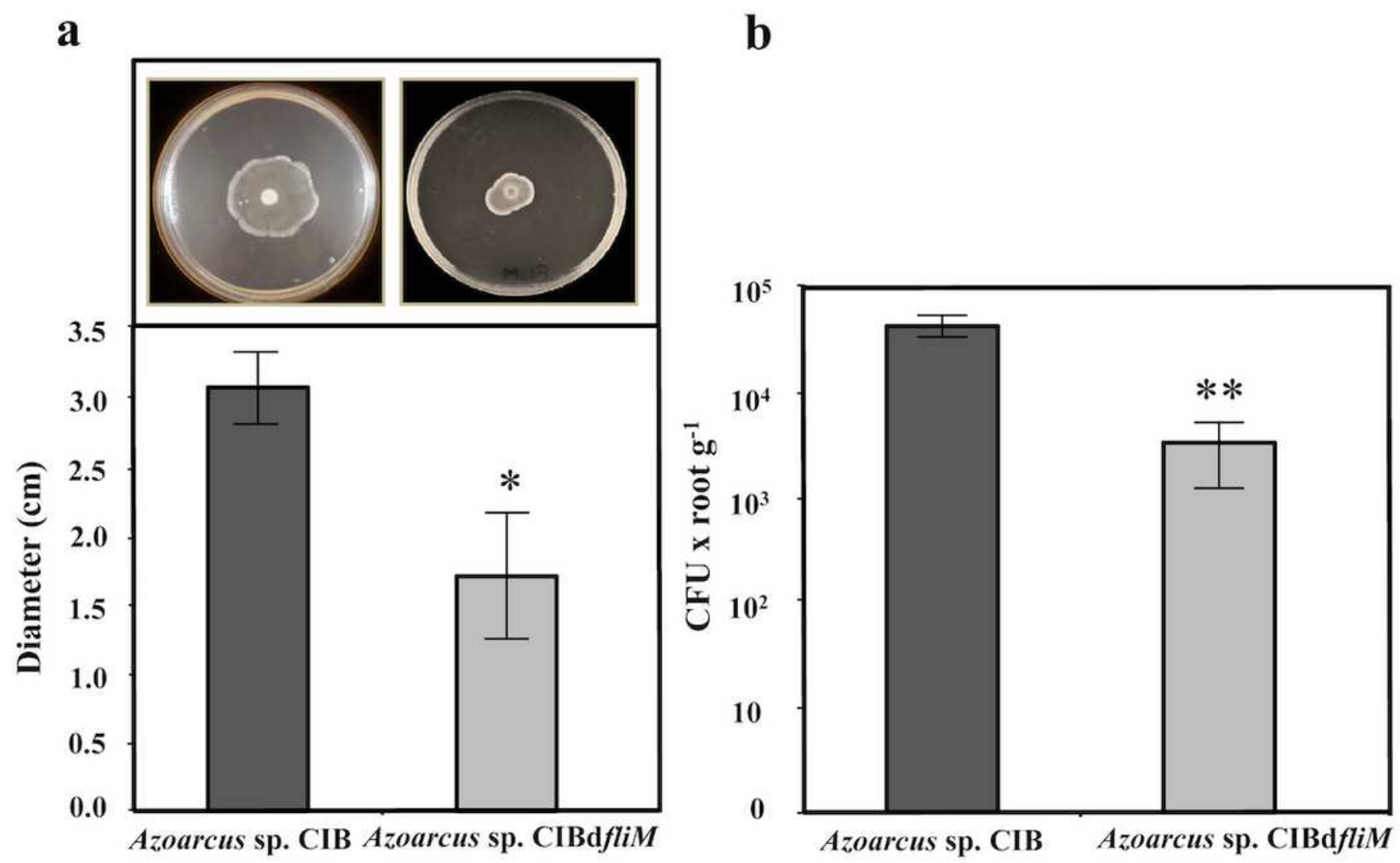

Figure 1

Swimming and rice colonization phenotypes of the Azoarcus sp. CIB and Azoarcus sp. ClBdfliM strains. a Swimming motility of the Azoarcus sp. CIB (carrying the control plasmid pSEVA237) and Azoarcus sp. CIBdfliM strains, and quantification of the diameter of the halos $(n=3)$; the error bars indicate the standard deviation. $b$ Quantification of the number of endophytes recovered from rice roots after inoculation with Azoarcus sp. CIB (pSEVA237) and Azoarcus sp. CIBdfliM strains. Graph shows the CFU values per gram of root (fresh weight) from three independent experiments \pm standard deviation. The asterisks show the significance of the differences observed when comparing the two strains and applying the statistical method of analysis of variance ANOVA and Bonferroni test $p<0.01(* *) ; p<0.05\left(^{*}\right)$. 
a

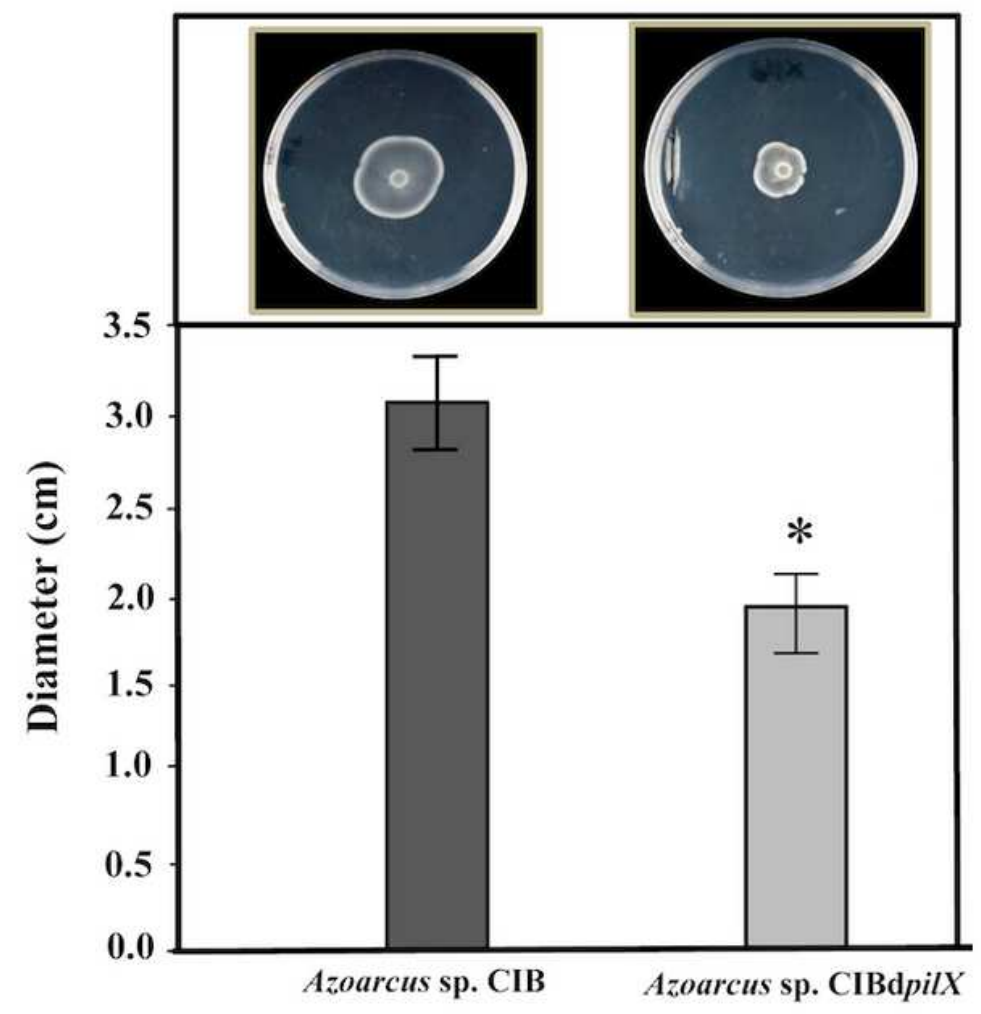

b

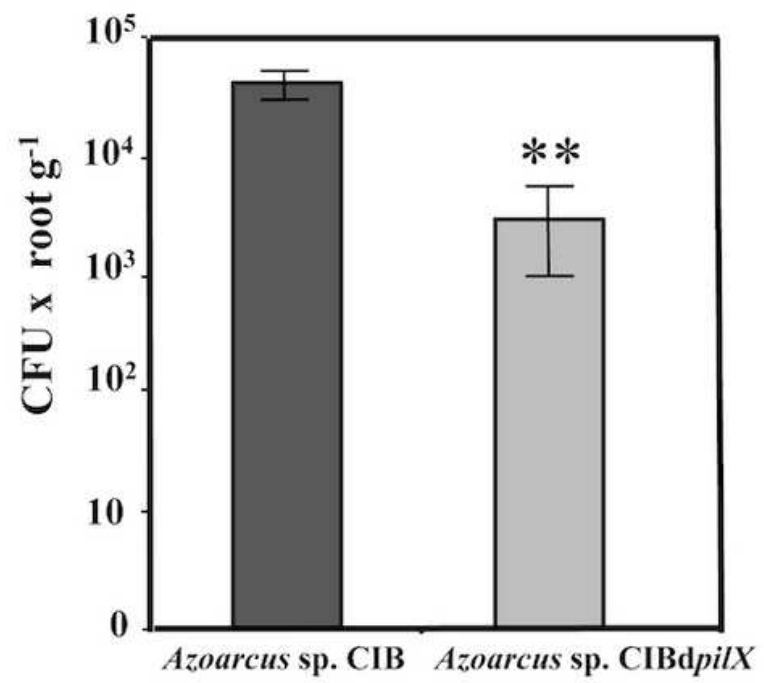

Figure 2

Motility and rice colonization phenotypes of the Azoarcus sp. CIB and Azoarcus sp. CIBdpilX strains. a Swarming motility of Azoarcus sp. CIB (carrying the control plasmid pSEVA237) (left) and Azoarcus sp. CIBdpilX (right), and quantification of the diameter of the halos $(n=3)$; the error bars indicate the standard deviation. $b$ Quantification of the number of endophytes recovered from rice roots after inoculation of rice seedlings with the Azoarcus sp. CIB (pSEVA237) and Azoarcus sp. CIBdpilX. The graph shows the CFU values per gram of root (fresh weight) of three independent experiments; error bars indicate standard deviation. Asterisks show the significance of the differences observed when comparing the two strains and applying the statistical method of ANOVA analysis of variance and Bonferroni test $p<0.01$ (**); $p$ $<0.05(*)$. 
a
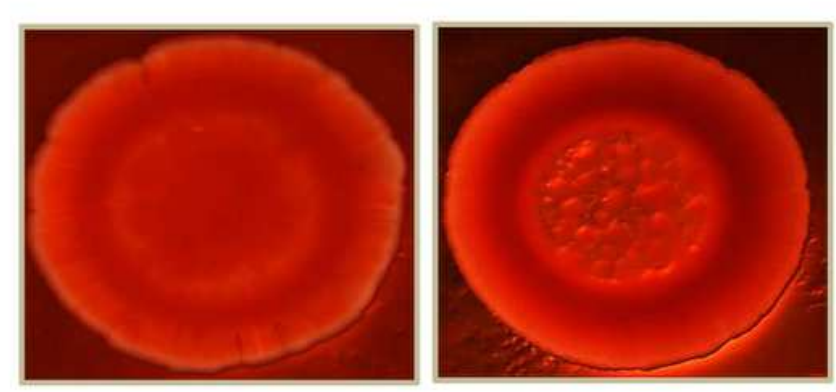

Azoarcus sp. CIB Azoarcus sp. CIBdepsF b

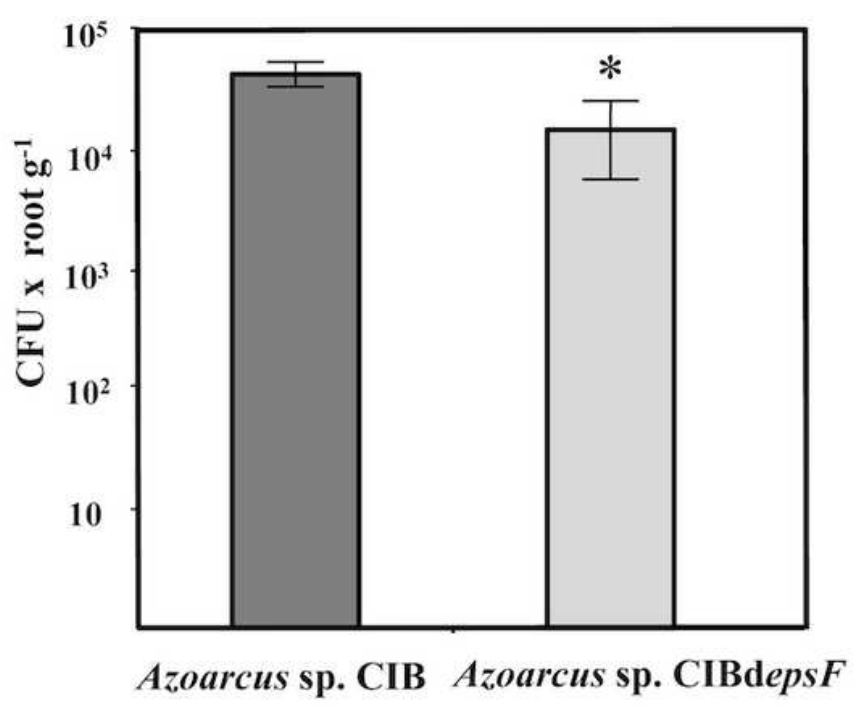

\section{Figure 3}

Colony morphology and rice colonization capacity of the Azoarcus sp. CIB and Azoarcus sp. CIBdepsF strains. a Morphology of the colonies of Azoarcus sp. CIB (pSEVA237) and Azoarcus sp. CIBdepsF strain grown in VM solid medium supplemented with Congo red $(0.5 \mathrm{~g} \mathrm{l}-1)$. The colonies were visualized with a Leica MZ16FA stereomicroscope. $b$ Quantification of the number of endophytes recovered from rice roots after inoculation with Azoarcus sp. CIB (pSEVA237) and Azoarcus sp. CIBdepsF strains. Graph shows the $\mathrm{CFU}$ values per gram of root (fresh weight) of three independent experiments \pm standard deviation. The asterisk shows the significance of the differences observed when comparing the two situations and applying the statistical method of ANOVA analysis of variance and Bonferroni test $\left.p<0.05{ }^{(}\right)$. 


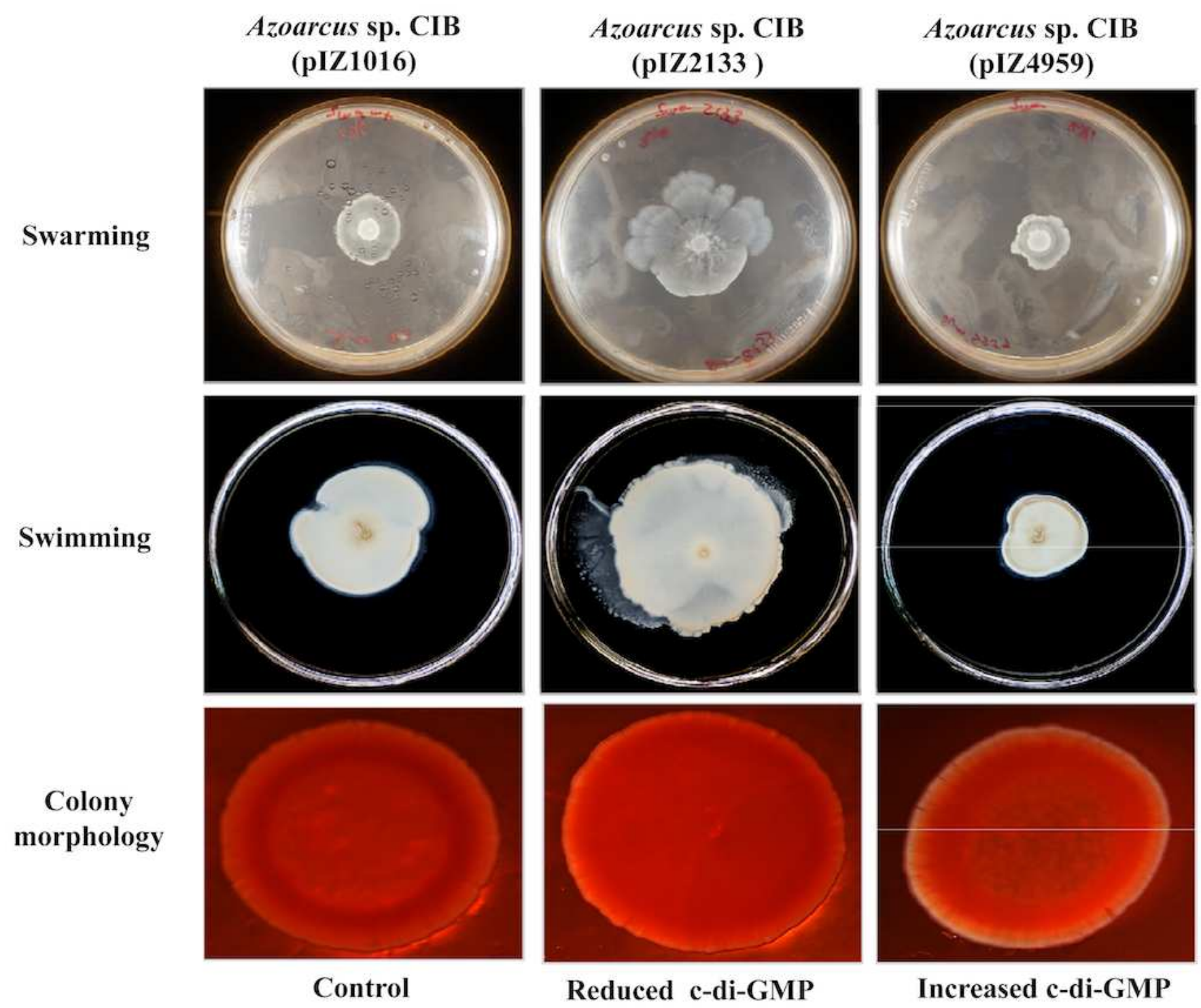

Figure 4

Motility and morphology of the colonies of Azoarcus sp. CIB strains expressing genes involved in the metabolism of c-di-GMP. The plates were inoculated with Azoarcus sp. CIB (plZ1016) (empty plasmid), Azoarcus sp. CIB (pIZ2133) (expressing the PA2133 phosphodiesterase) and Azoarcus sp. CIB (pIZ4959) (expressing the PP4959 diguanylate cyclase). 


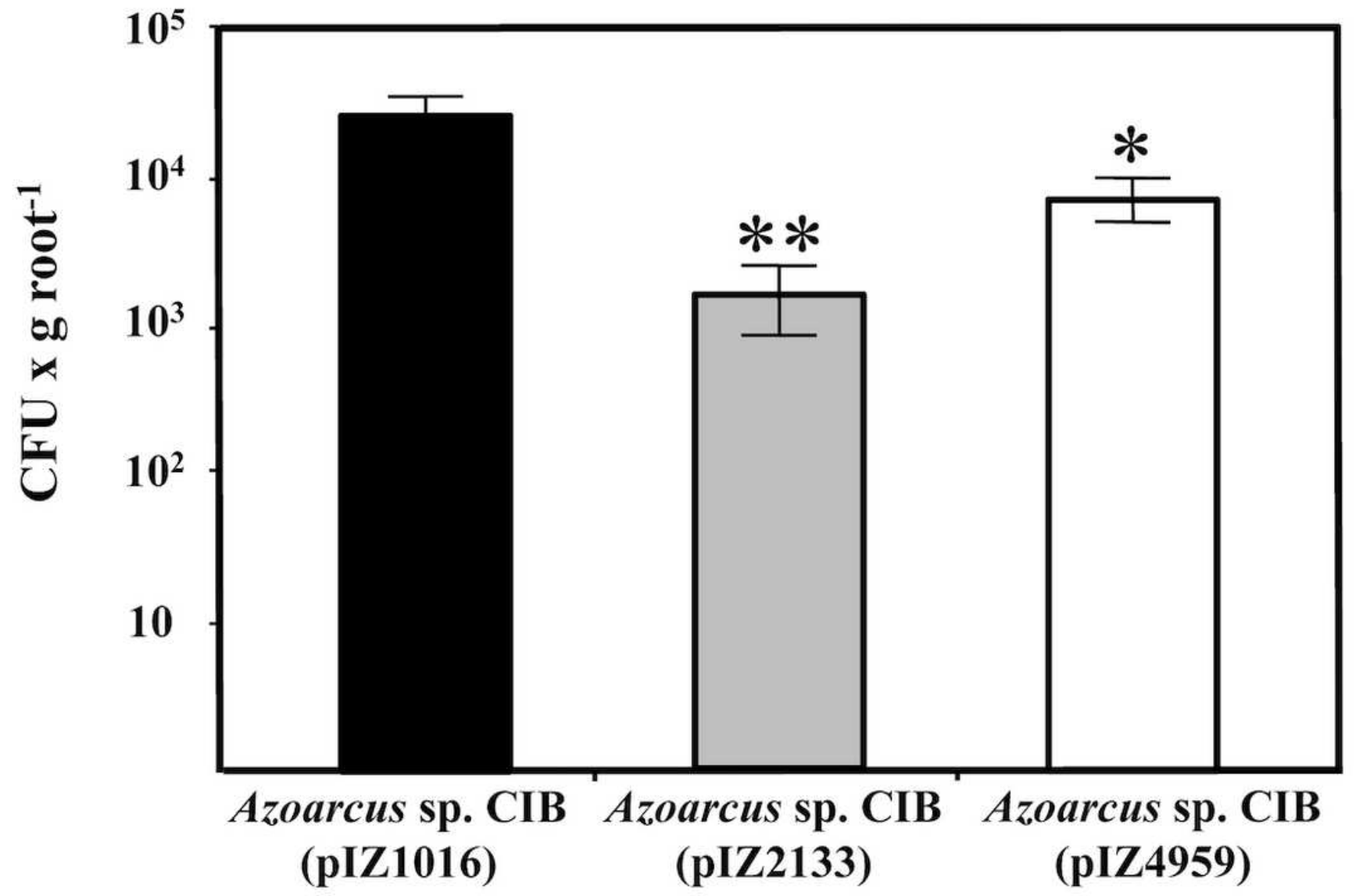

Figure 5

Rice roots colonization by Azoarcus sp. CIB strains producing different levels of c-di-GMP. Rice seedlings were inoculated with Azoarcus sp. CIB (pIZ1016) (empty plasmid), Azoarcus sp. CIB (plZ2133) (expressing the PA2133 phosphodiesterase) and Azoarcus sp. CIB (plZ4959) (expressing the PP4959 diguanylate cyclase). Plants were grown at $25^{\circ} \mathrm{C}$ for 5 days and bacteria present inside the roots were determined as described in Methods. The graph shows the CFU values per gram of root (fresh weight) of three independent experiments; error bars represent the standard deviation. Asterisks show the significance of the differences observed when comparing the strains with modified levels of c-di-GMP with respect to the control strain and applying the statistical method of ANOVA analysis of variance and Bonferroni test $p<0.01\left({ }^{* *}\right) ; p<0.05(*)$. 


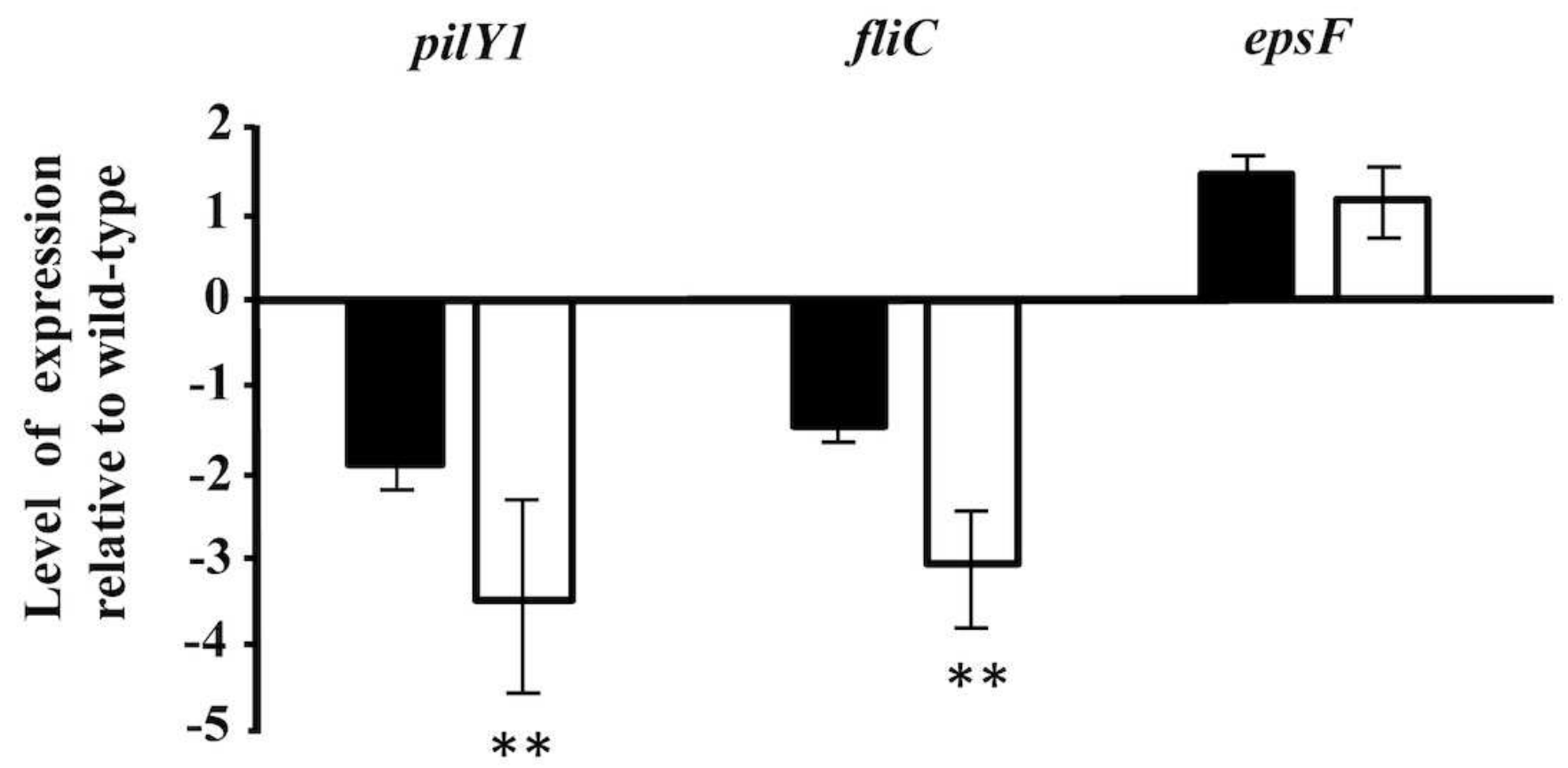

Figure 6

Expression of the pilY1, fliC and epsF genes in Azoarcus sp. CIB strains producing different levels of c-diGMP. The transcript levels of the pilY1, fliC and epsF genes in the Azoarcus sp. CIB (plZ2133) (black columns) and Azoarcus sp. CIB (pIZ4959) (white columns) strains grown in VM-ethanol medium for $24 \mathrm{~h}$, were determined by quantitative RT-PCR using dnaE gene as internal control, as detailed in Methods. The expression of the genes in each strain is shown relative to their expression in the control strain Azoarcus sp. CIB (plZ1016). The mean value and the standard deviation corresponding to the results of three independent experiments are indicated. Asterisks show the significance of the differences observed when comparing the level of expression of modified strains with respect to wild-type strain applying the statistical method of ANOVA analysis of variance and Bonferroni test $p<0.01$.

\section{Supplementary Files}

This is a list of supplementary files associated with this preprint. Click to download.

- Additionalfile1.pdf 